\title{
Gas Chromatography Mass Spectrometry and Fourier transform Infrared Spectroscopy analysis of methanolic extract of Mimosa pudica L. leaves
}

\author{
Ahamefula A. Ahuchaogu ${ }^{1 *}$, Godwin I. Ogbuehi ${ }^{1}$, P.O. Ukaogo ${ }^{1}$ and Ifeanyi. E. Otuokere ${ }^{2}$ \\ ${ }^{1}$ Department of Pure and Industrial Chemistry, Abia state University, Uturu, Nigeria. \\ ${ }^{2}$ Department of Chemistry, Michael Okpara University of Agriculture, Umudike, Nigeria. \\ ${ }^{*}$ Corresponding author. Email: ahuchaogua@gmail.com
}

Copyright (C) 2020 Ahuchaogu et al. This article remains permanently open access under the terms of the Creative Commons Attribution License 4.0, which permits unrestricted use, distribution, and reproduction in any medium, provided the original work is properly cited.

Received 13th March, 2020; Accepted 14th April, 2020

\begin{abstract}
The present study investigates the chemical constituents of a traditionally used ethno-medicinal plant Mimosa pudica Linn using Gas Chromatography Mass Spectrometry (GC/MS) and Fourier Transform Infrared Spectroscopy (FTIR). The identification of phytochemical compounds was based on the peak area, retention time, molecular weight, molecular formula, MS fragment ions. Thirteen phytochemical compounds were identified in the methanolic extract of leaves Mimosa pudica. The GC-MS analysis provide the existence of N, N'-Bis (Carbobenzyloxy)lysine methyl(ester, Acetamide, N-methyl-N-[4-[4-fluoro-1-hexahydropyridyl]-2-butynyl]-, o-Ethylhydroxylamine, Propanamide, 2-hydroxy-, 1-Allyl-4-(4-methoxyphenyl)-1H-pyrimidin-2-thion, Gentamicin a, Mannosamine, 1H-Indole, 4(3-methyl-2-butenyl)-. The FT-IR analysis revealed the presence of carbonyl $(\mathrm{C}=\mathrm{O})$ at $1705.3 \mathrm{Cm}^{-1}$, aliphatic stretching $(\mathrm{C}-\mathrm{H})$ at $2978.8 \mathrm{Cm}^{-1}$ and $2944 \mathrm{Cm}^{-1}$ and hydroxyl functional group $(\mathrm{O}-\mathrm{H})$ at $3313.6 \mathrm{Cm}^{-1}$ These chemical compounds may exhibit various therapeutic properties such as antifungal, antibacterial, anti- inflammatory, anti-oxidant and others.
\end{abstract}

Keywords: FT-IR, GC-MS, leaf extract, medicinal plants, Mimosa pudica.

\section{INTRODUCTION}

Plant-derived products have been used as therapeutic alternatives in the health-care systems of several countries. Medicinal plants are important sources of biologically active compounds, as their easy access, affordability and high safety margin are some of the main reasons that justifies their widespread application (CortésRojas et al., 2013). The use of medicinal plants or their extracts for treatment of various infectious and noninfectious ailments in traditional communities have increased tremendously in recent times globally. It has been estimated that about $80 \%$ of world population use herbal remedies for treatment and control of diseases (Ekaiko et al., 2016). This provides a rationalization for research on medicinal plant extracts as a possible source of alternative therapy against communicable and noncommunicable diseases. There is a renewed interest in traditional medicine and an increasing demand for more drugs from plant sources. The resurgence of interest in plant derived drugs is mainly due to the current widespread belief that green medicine is safe and more dependable than the costly synthetic drugs, many of which have adverse side effects (Okwulehie and Akanwa, 2013). In many developing countries, including Nigeria, about $80 \%$ of people use indigenous herbal remedies to treat infectious diseases. Despite the availability of modern medicine in some communities, herbal medicines (medicinal plants) have continued to maintain popularity for historical and cultural reasons, in addition to their safety, efficacy and cheaper cost (Anyanwu and Okoye, 2017). They also represent sources of potentially important new pharmaceutical substances since all parts of a plant, from roots to seed heads and flowers, are employed in traditional remedies and can therefore, act as sources of lead compounds (Lifongo et al., 2014). A large majority of these plants are herbaceous, while some are trees, weeds and shrubs. These medicinal plants are 
found in the wild, semi wild and in cultivated habitat. Many of these indigenous medicinal plants are consumed as foods (Faleye and Ogundaini, 2012). The therapeutic uses of plant extracts or chemicals derived from plants have become the natural blue print for the development of new drugs (Edoga et al., 2005). The medicinal values of these plants are determined by their phytochemical constituents, which produce definite and diverse physiological and pharmacological response in the human body (Ekanem and Udo, 2009; Edoga et al., 2005).

Across the continent, many medicinal plants have gone into extinction before documentation. There is rapid depletion of these natural plant resources due to over exploitation, large scale deforestation, unsustainable arable land use, urbanization, industrialization and lack of conservation programs. Also, due to fear of lack of patronage and to mystify their trade, the traditional medicine practitioners hide the identity of medicinal plants and discourage its use, leading to a huge loss in the knowledge of these plants (Obute and Osuji, 2002). Plant materials could be referred to as natural anti-cancer, hemostatic agent, anti-inflammatory and antibiotic reservoir and the development of resistance by pathogens to various antibiotics has rekindled interest into the medicinal importance of plant.

Mimosa pudica L (Family: Fabaceae), a creeping annual or perennial herb often grown for its curiosity value as the leaves fold inward and droop when touched and again reopens within minutes. It is also called a humble plant, shame plant and touch me not plant. This plant is said to have a bitter and astringent taste and has a history of use for the treatment of various ailments. The most commonly used plant part for this purpose is the leaves, but flowers, bark and fruits are also important in forklore medicine (Sriram et al., 2011).

M. pudica, Linn leaves are widely used as an antidepressant and anti-asthmatic in the management of wide range of ailments (Rohini and Srikum, 2014; McDonald and Prenzler, 2011). Pharmacological studies have also revealed that $M$. pudica contains metabolites such as phenols and flavonoids compounds which possess anticancer and antidiabetic activities (Zhang et al., 2011). It also reduces toothache by using a decoction of root with water. It is used to arrest bleeding and fasten the wound healing process and in herbal preparation for a gynecological disorder (Coimbra and Magnanini,1993). It is beneficial in the treatment of diarrhea, amoebic dysentery and has been researched to have medicinal properties to cure skin diseases. Studies have shown that it is also used to treat neurological problems (Patro et al., 2016). Studies have also shown that $M$. pudica is used to relax the mind, relieves depression, mental distress, irritability and amnesia. It is also used to enhance mood and improves the circulation of blood. It also promotes healthy cell growth and prevents baldness. In western medicine, its root was used for the treatment of insomnia, irritability, premenstrual syndrome hemorrhoids and whooping cough (Varnika et al., 2012).

Thus, the present study was carried out to investigate the chemical constituents of Mimosa pudica L using a Gas Chromatography Mass Spectrometry (GC/MS) and Fourier Transform Infrared Spectroscopy (FTIR)

\section{MATERIALS AND METHODS}

\section{Sample collection}

The leaves of Mimosa pudica $L$ were harvested from the field of National Root Crop Research Institute, Umudike Abia State, Nigera on the 14th October, 2019. Authentication of plant materials was carried out by Dr. O. Emmanuel at the Department of Plant Science and Biotechnology, Abia State University, Uturu, Nigeria. Voucher specimen [MP 1578] was deposited at the herbarium of the Botanical Department of Biological Sciences School of the same University.

\section{Preparation of plant leaves}

The plant leaves (Figure 1) were washed with running tap water for 5 minutes to remove the dust and debris and rinsed with sterile distilled water. The fresh plant leaves sample was air dried on the laboratory bench for fifteen days at temperature below $30^{\circ} \mathrm{C}$ to avoid decomposition of thermo labile compounds. The sample was milled using and electric blender to coarse powder and powdered sample was kept in a clean closed container pending extraction. $50 \mathrm{~g}$ of pulverized leaf material was mixed with $150 \mathrm{ml}$ of solvent (95\% methanol) and kept in rotary shaker at $100 \mathrm{rpm}$ overnight and filtered with What man No.1 filter paper. The extract was concentrated under reduced pressure using Digital Heidolph Rotary evaporator (4000 series) and the supernatant plant extract was decanted after complete removal of the solvent.

\section{GC-MS analysis}

The GC-MS analysis of the methanol leaf extract of Mimosa pudica L was carried out using a HP 7890 GC instrument integrated with an Agilent 5975C MSD mass spectrometer (Aligent, Santa Clara, CA, USA). The capillary column was an Agilent HP-5MS (30 m x $0.25 \mathrm{~mm}$ i.d. $x 0.25$ NM film thickness), Helium (purity $>99.999 \%$ ) was used as the carrier gas, and the flow rate was 1 $\mathrm{mL} / \mathrm{min}$. The injector temperature was $250^{\circ} \mathrm{C}$, and the injection mode was split less. The G.C oven temperature was held at $50^{\circ} \mathrm{C}$ for 5 minutes, which was increased to $210^{\circ} \mathrm{C}$ at a rate of $3^{\circ} \mathrm{C} /$ minutes, maintained at $210^{\circ} \mathrm{C}$ for 3 minutes, and finally increased to $230^{\circ} \mathrm{C}$ at $150^{\circ} \mathrm{C}$ /minutes. The mass spectrometer conditions were as follow: ionization energy, $70 \mathrm{eV}$; ion source temperature, $230^{\circ} \mathrm{C}$; 


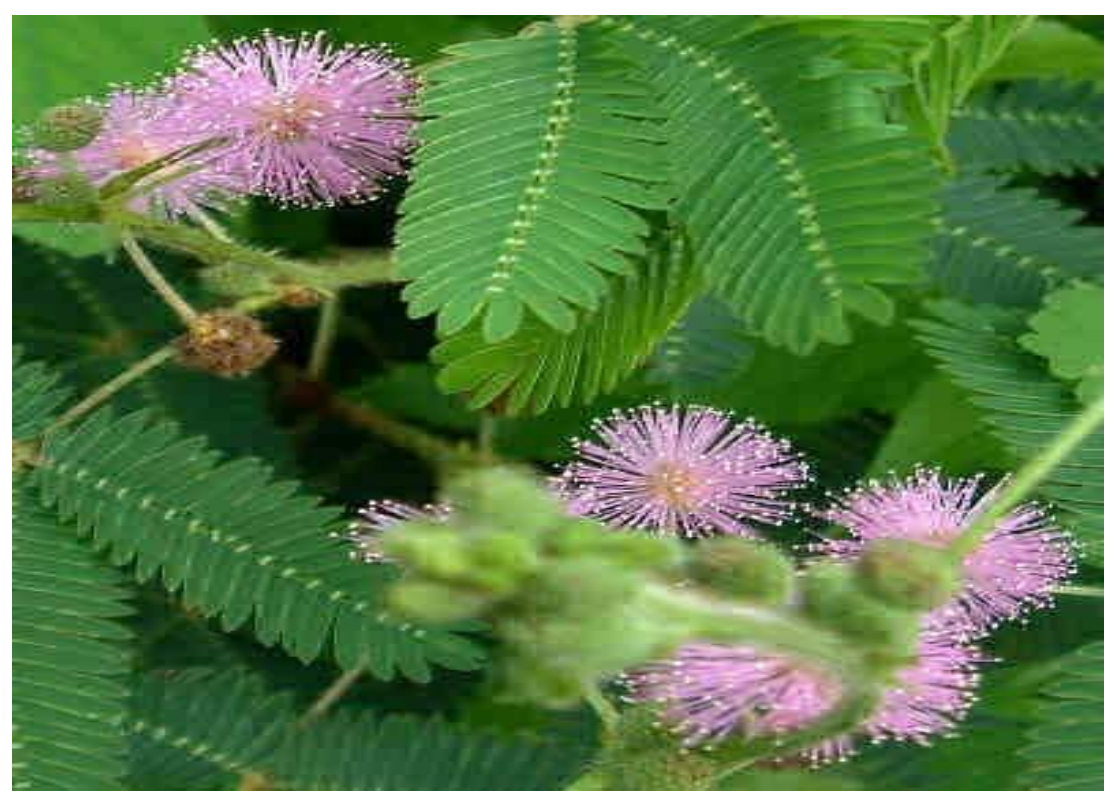

Figure 1. Mimosa pudica, leaves, flowers and stem.

quadruple temperature, $150^{\circ} \mathrm{C}$; quadruple mass spectrometer scan range 30 to 500 atomic mass units (amu); solvent delay time 2.8 minutes.

\section{Identification of compounds}

The components of the methanol extract of Mimosa pudica $L$ was identified by matching the peaks with computer Wiley Ms. libraries and confirmed by comparing mass spectra of the peaks and those from literature (Ahamefula et al., 2018).

\section{FTIR Spectroscopic analysis}

FTIR analysis was performed using Perkin Elmer spectrophotometer system, which was used to detect the characteristic peaks and their functional groups using Attenuated Total Reflectance (ATR) accessory. The IR scan was performed in the wave number region of 4000 $550 \mathrm{~cm}^{-1}$ (mid- infrared range).

\section{RESULTS AND DISCUSSION}

Gas Chromatography - Mass Spectrometry (GC-MS) is a method that combines the features of gas chromatography and mass spectrometry to separate different substances within a test sample based on their retention time (Kell et al., 2005). In recent times, GC-MS has become well recognized as a key technological platform for secondary metabolite profiling in both plant and non-plant materials (Fernie et al., 2004). In this study, the active principles with their retention time (RT), molecular formula, molecular weight (MW), concentration (peak area \%) are presented in Figures $2 \mathrm{~A}$ to $2 \mathrm{M}$, which shows the presence of 13 bioactive phytochemical compounds in the methanol extract of Mimosa Pudica. The presence of various phytocompounds on the methanol leaf extract can be attributed to its widely use in folklore medicines, especially in arresting wound bleeding and fasten the wound healing process (Chinmoy and Nongmaithem, 2019). Hafsa et al. (2012) reported the presence of bioactive components such as terpenoids, flavonoids, glycosides, alkaloids, quinines, phenols, tannins, saponins, and coumarins on $M$. pudica methanol leaf extract. Among the identified phytocompounds are Acetamide, N-methyl-N-[4-[4-fluoro1-hexahydropyridyl]-2-butynyl]-, Gentamicin and mannosamine have antioxidant and antimicrobial activities (Hussein et al., 2019). On other hand, compounds with acetamide linkage exhibit variety of applications, which are well documented. The acetamide functional group is responsible for antimicrobial (Berest et al., 2011) antioxidant and anti-inflammatory (Autore et al., 2010). The acetamides and their analogues are also well studied as chemotherapeutic agents (McCarthy et al., 2009; Liu et al., 2012).

The Fourier Transform Infrared Spectroscopy was used to identify the functional groups as presented in Figure 3 and Table 1. Figure 3 Shows the FTIR spectrum of $M$. pudica methanol leaf extract. The peak at $3313.6 \mathrm{~cm}^{-1}$ revealed the presence of alcohols, phenols $(\mathrm{O}-\mathrm{H}$ stretch, $\mathrm{H}$-bonded). The peak at 2978.8 and $2944.8 \mathrm{~cm}^{-1}$ refers to the presence of alkanes (C-H stretch). The peak at 1705.3 $\mathrm{cm}^{-1}$ corresponds carboxylic acid group ( $\mathrm{C}=\mathrm{O}$ stretch). $\mathrm{A}$ peak at $1559.906 \mathrm{~cm}^{-1}$ shows the presence of alkene and aromatic compound $(\mathrm{C}=\mathrm{C}$ bend). The results of $\mathrm{FT}-\mathrm{IR}$ spectroscopy confirm the presence of various chemical 


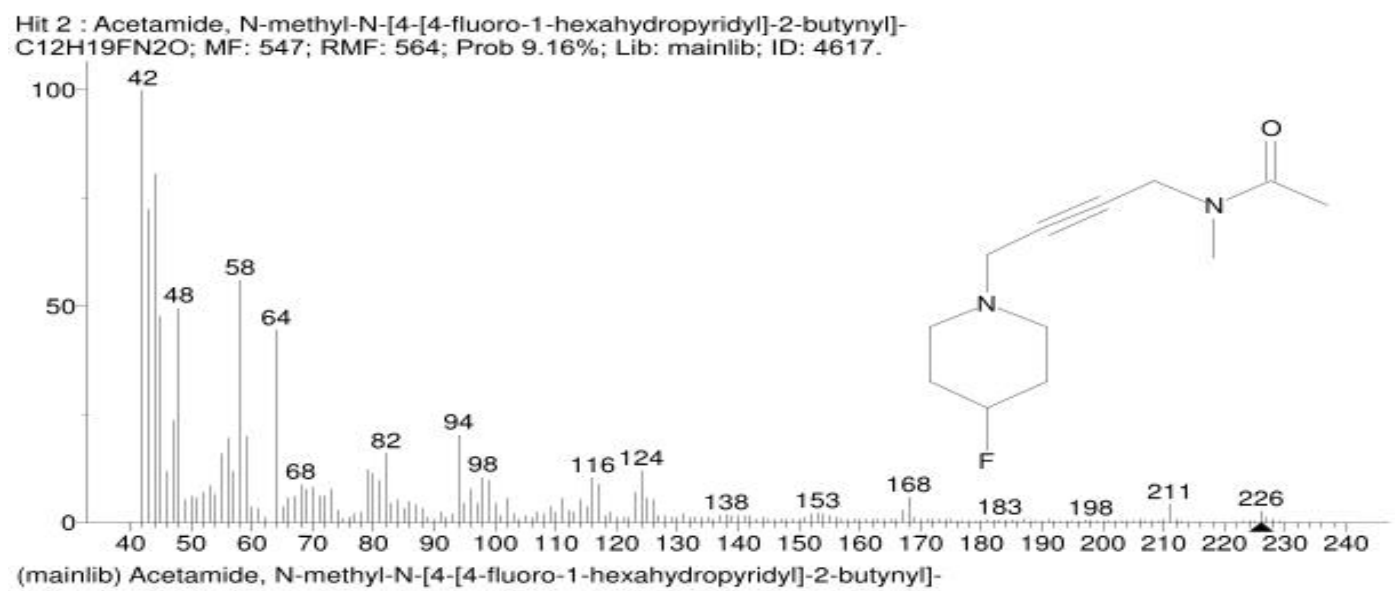

(mainlib) Acetamide, $\mathrm{N}$-methyl- $\mathrm{N}$-[4-[4-fluoro-1-hexahydropyridyl]-2-butynyl]-

Figure 2A. The Mass spectra of methanol leaves extract of Mimosa Pudica LINN.

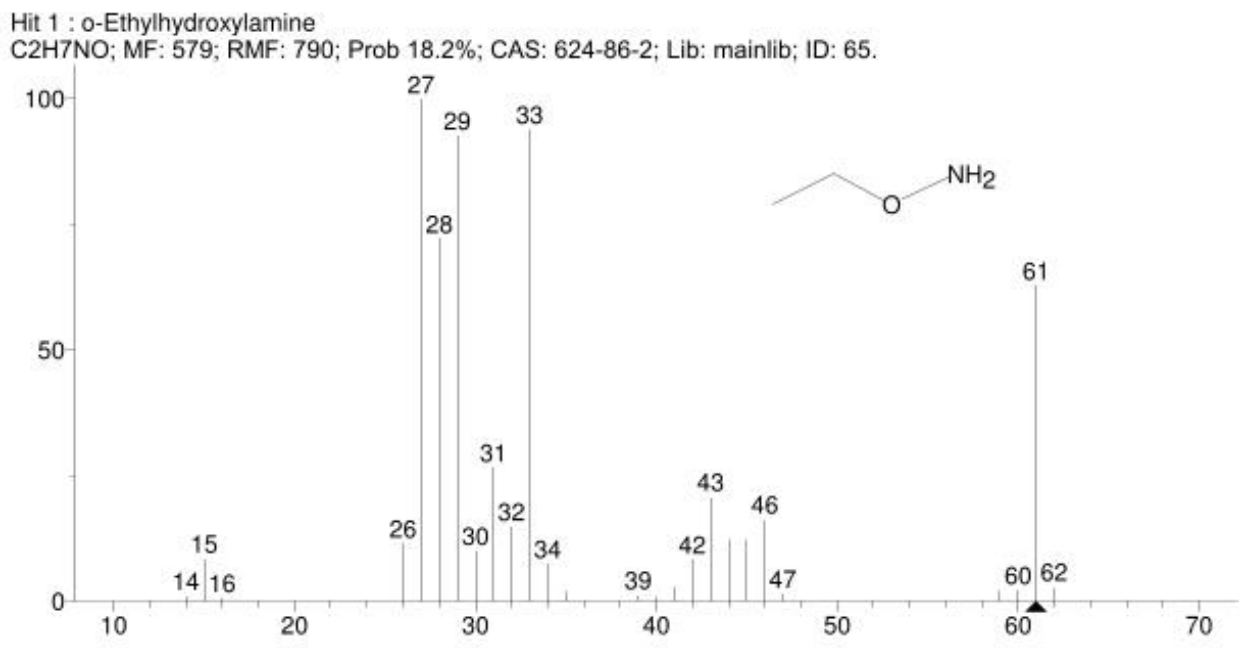

(mainlib) o-Ethylhydroxylamine

Figure 2B. The Mass spectra of methanol leaves extract of Mimosa Pudica LINN.

Hit 2 : Propanamide, 2-hydroxy-

C3H7NO2; MF: 576; RMF: 765; Prob 16.1\%; CAS: 2043-43-8; Lib: mainlib; ID: 16937.

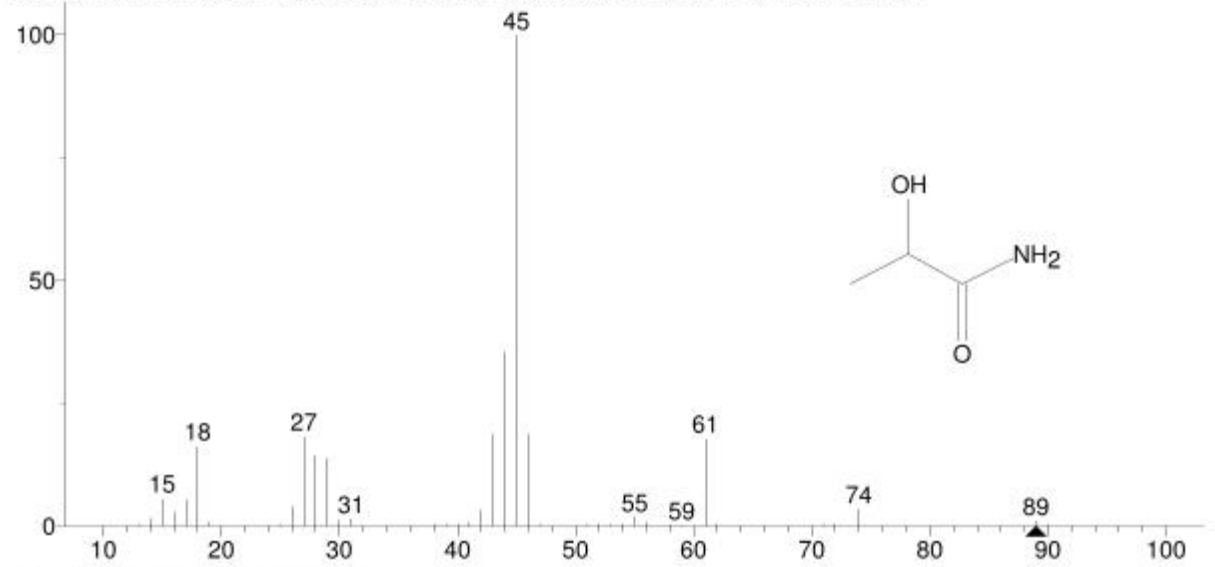

(mainlib) Propanamide. 2-hvdroxv-

Figure 2C. The Mass spectra of methanol leaves extract of Mimosa pudica LINN. 


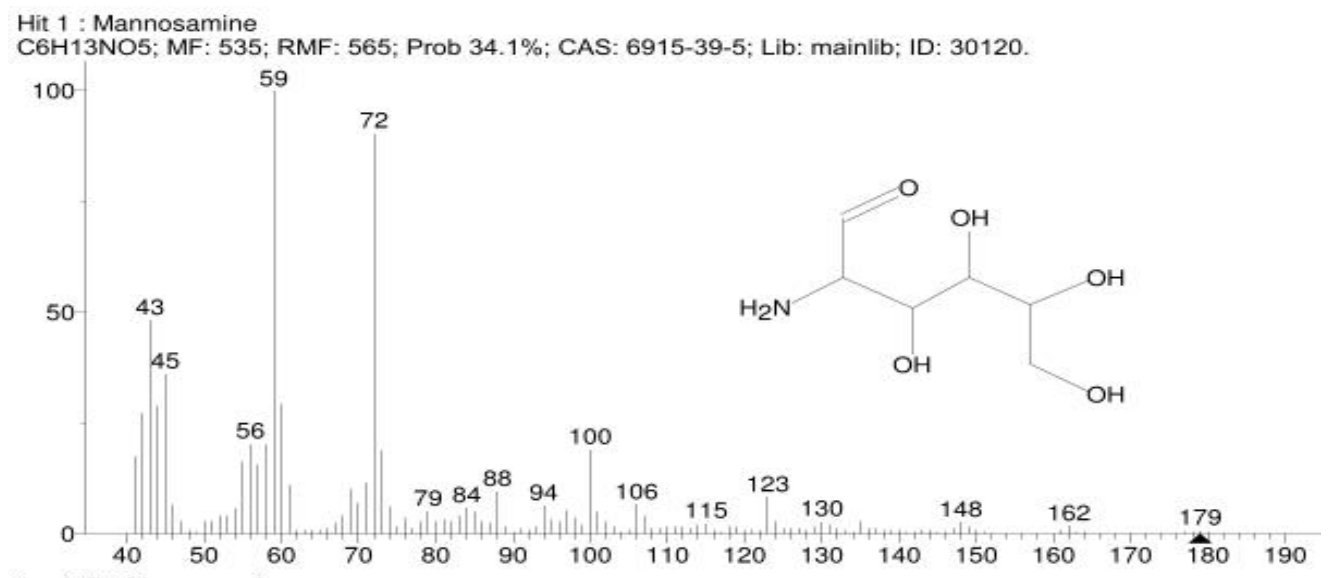

(mainlib) Mannosamine

Figure 2D. The Mass spectra of methanol leaves extract of Mimosa pudica LINN.

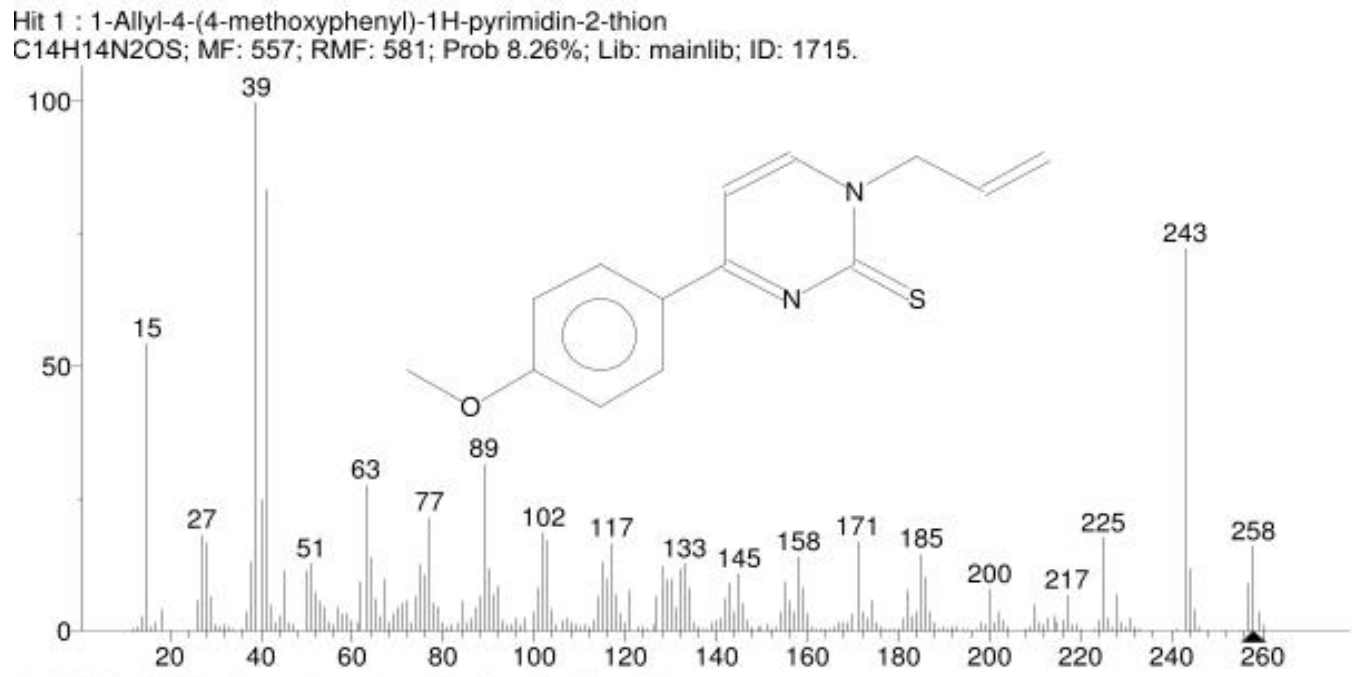

(mainlib) 1-Allyl-4-(4-methoxyphenyl)-1H-pyrimidin-2-thion

Figure 2E. The Mass spectra of methanol leaves extract of Mimosa pudica LINN.

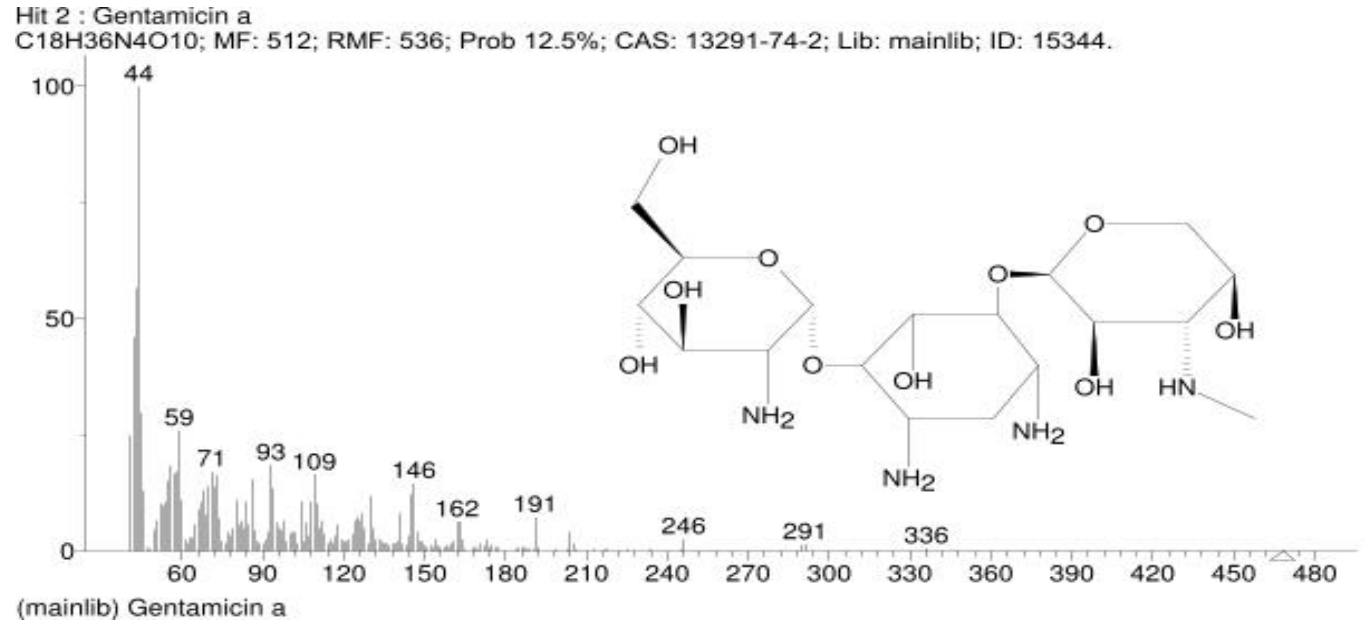

Figure 2F. The Mass spectra of methanol leaves extract of Mimosa pudica LINN. 


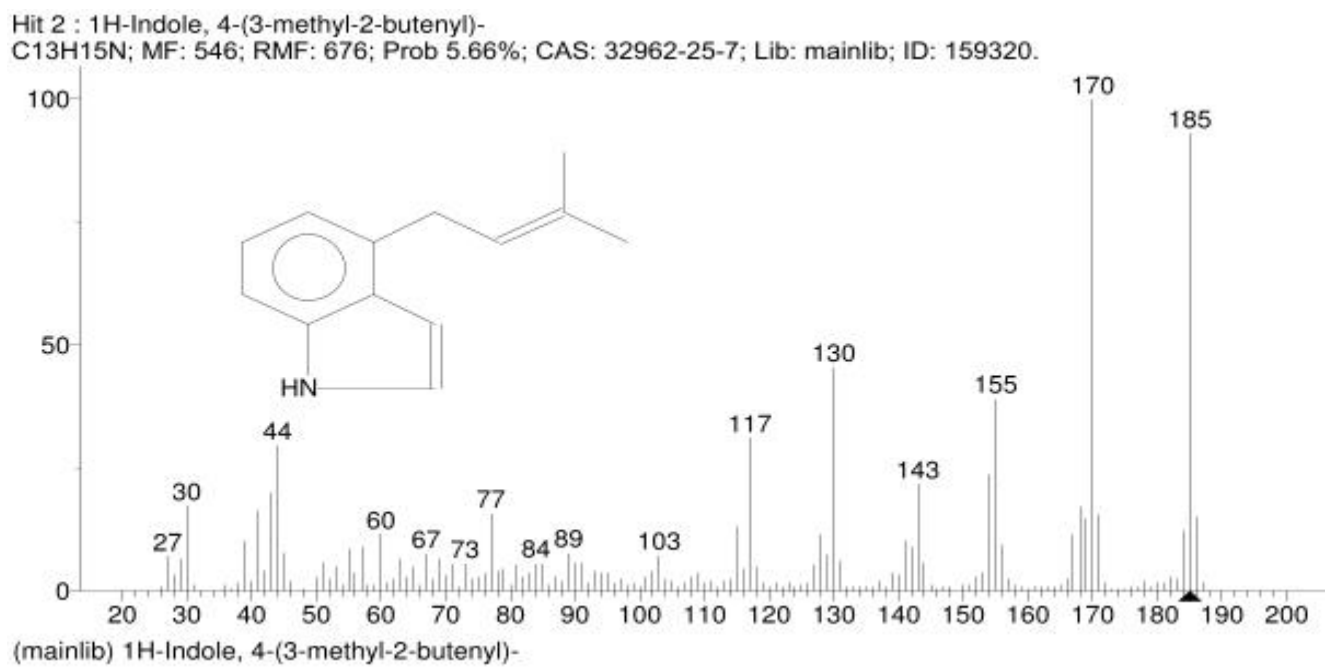

Figure 2G. The Mass spectra of methanol leaves extract of Mimosa pudica LINN.

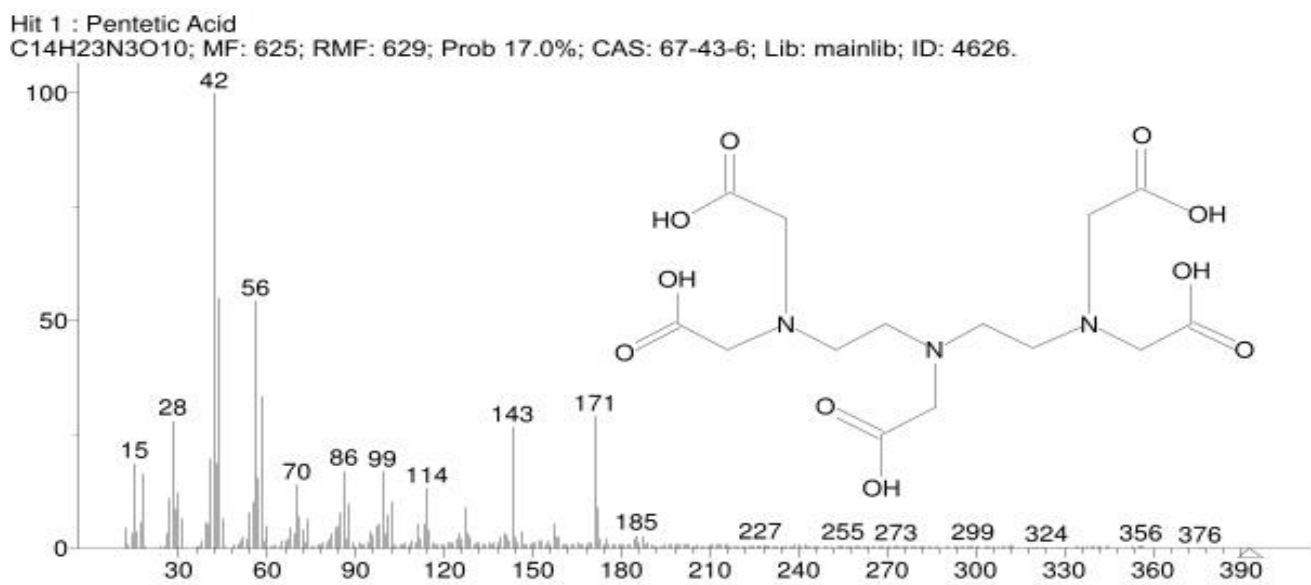

(mainlib) Pentetic Acid

Figure $\mathbf{2 H}$. The Mass spectra of methanol leaves extract of Mimosa pudica LINN.

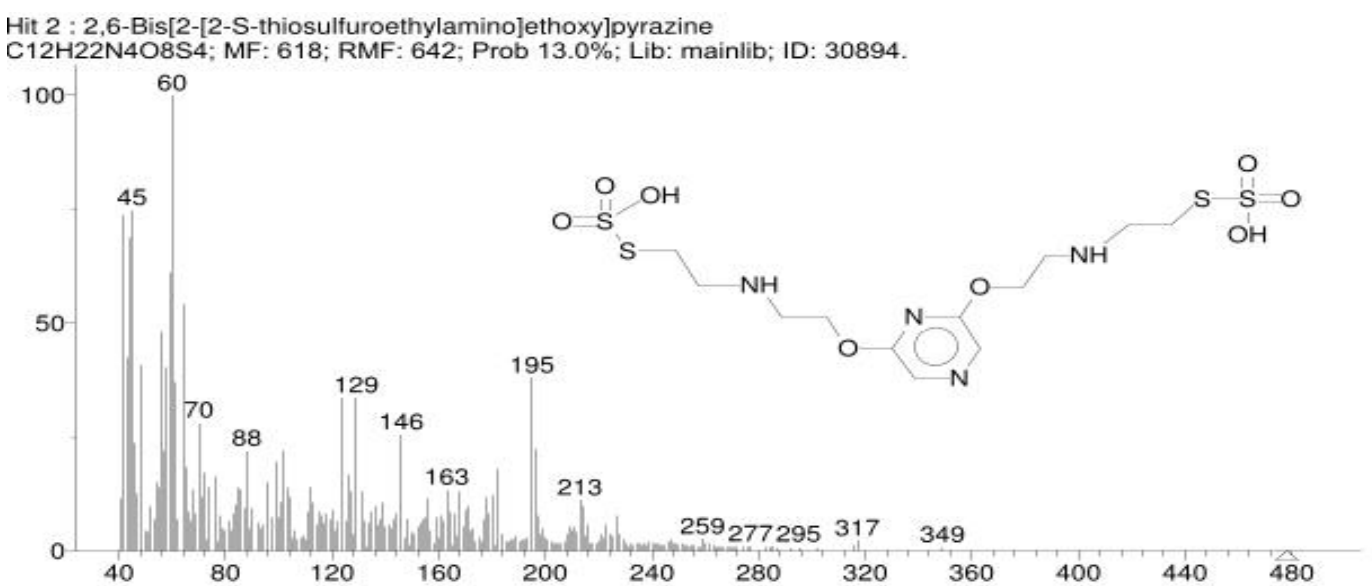

(mainlib) 2,6-Bis[2-[2-S-thiosulfuroethylamino]ethoxy]pyrazine

Figure 2I. The Mass spectra of methanol leaves extract of Mimosa pudica LINN. 


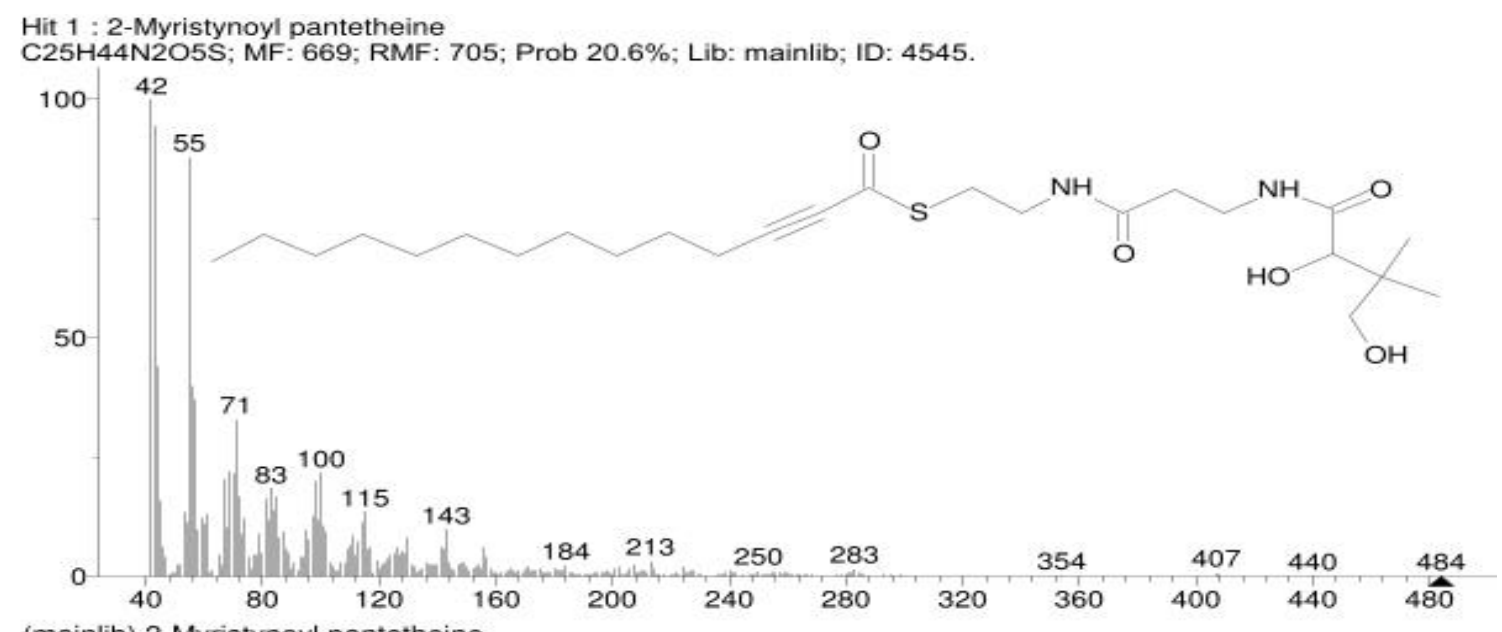

(mainlib) 2-Myristynoyl pantetheine

Figure 2J. The Mass spectra of methanol leaves extract of Mimosa pudica LINN.

Hit 1 : Pentetic Acid

C14H23N3O10; MF: 625; RMF: 629; Prob 17.0\%; CAS: 67-43-6; Lib: mainlib; ID: 4626.

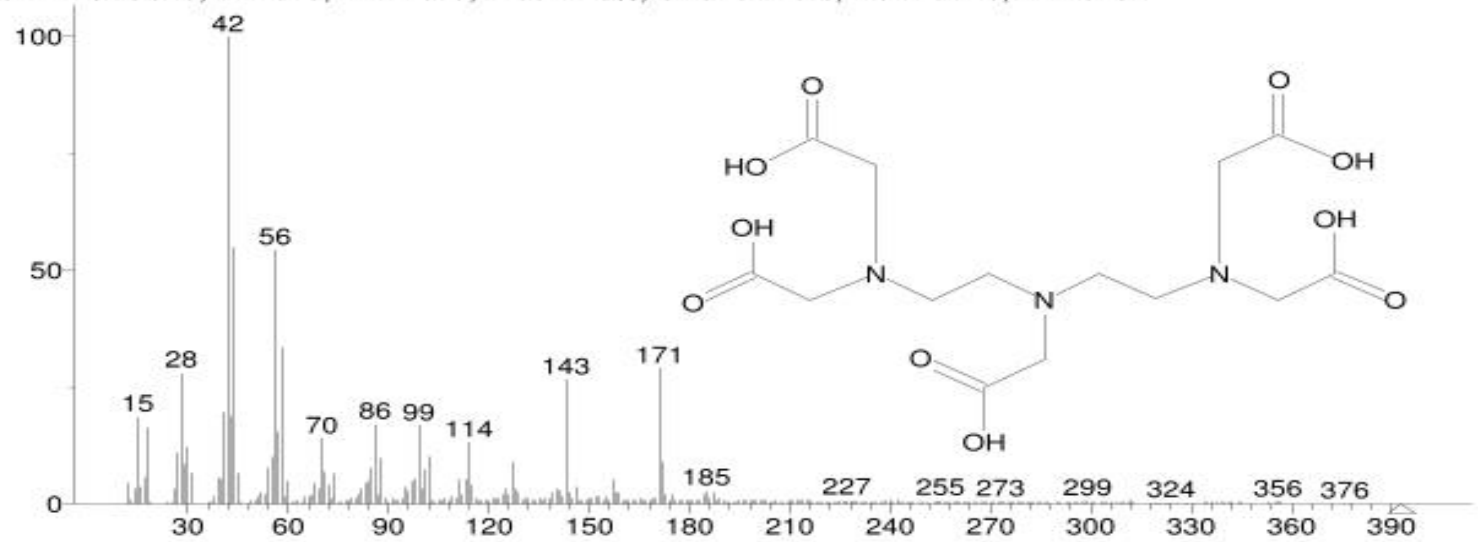

(mainlib) Pentetic Acid

Figure 2K. The Mass spectra of methanol leaves extract of Mimosa pudica LINN.

Hit 1 : N,N'-Bis(Carbobenzyloxy)-lysine methyl(ester)

C23H28N2O6; MF: 597; RMF: 630; Prob 13.3\%; Lib: mainlib; ID: 59074.

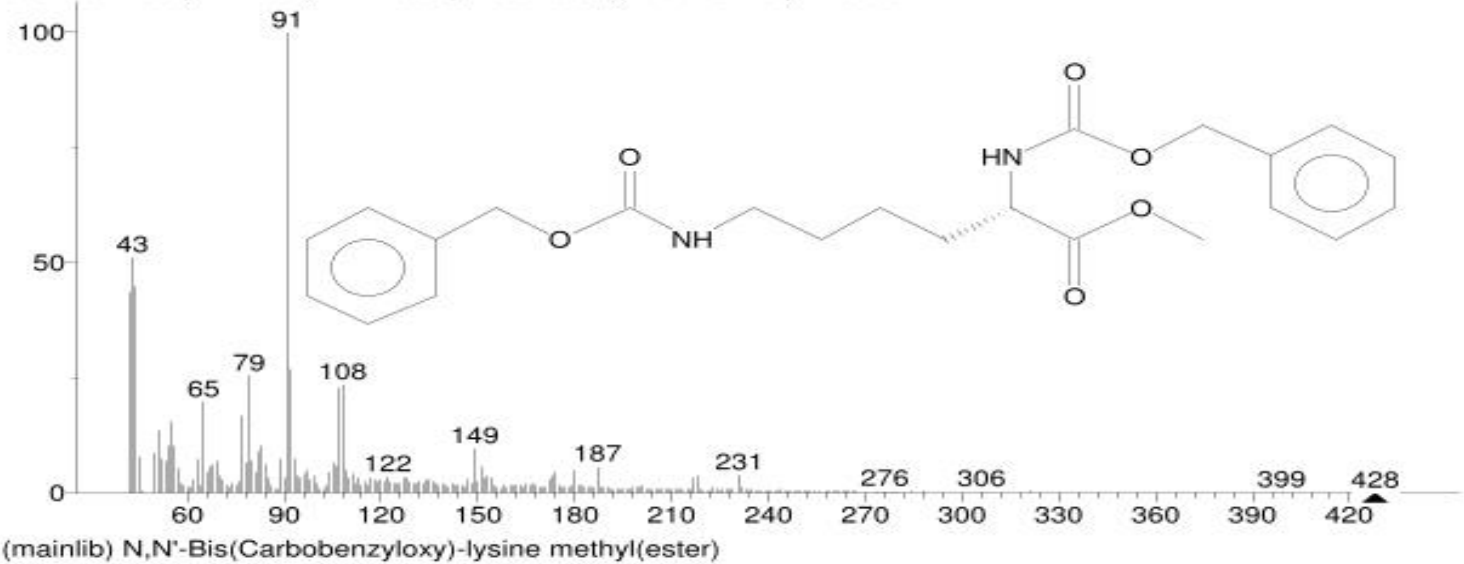

(mainlib) N,N'-Bis(Carbobenzyloxy)-lysine methyl(ester)

Figure 2L. The Mass spectra of methanol leaves extract of Mimosa pudica LINN. 
Hit 2 : 2,6-Bis[2-[2-S-thiosulfuroethylamino]ethoxy]pyrazine

C12H22N4O8S4; MF: 596; RMF: 630; Prob 12.8\%; Lib: mainlib; ID: 30894.

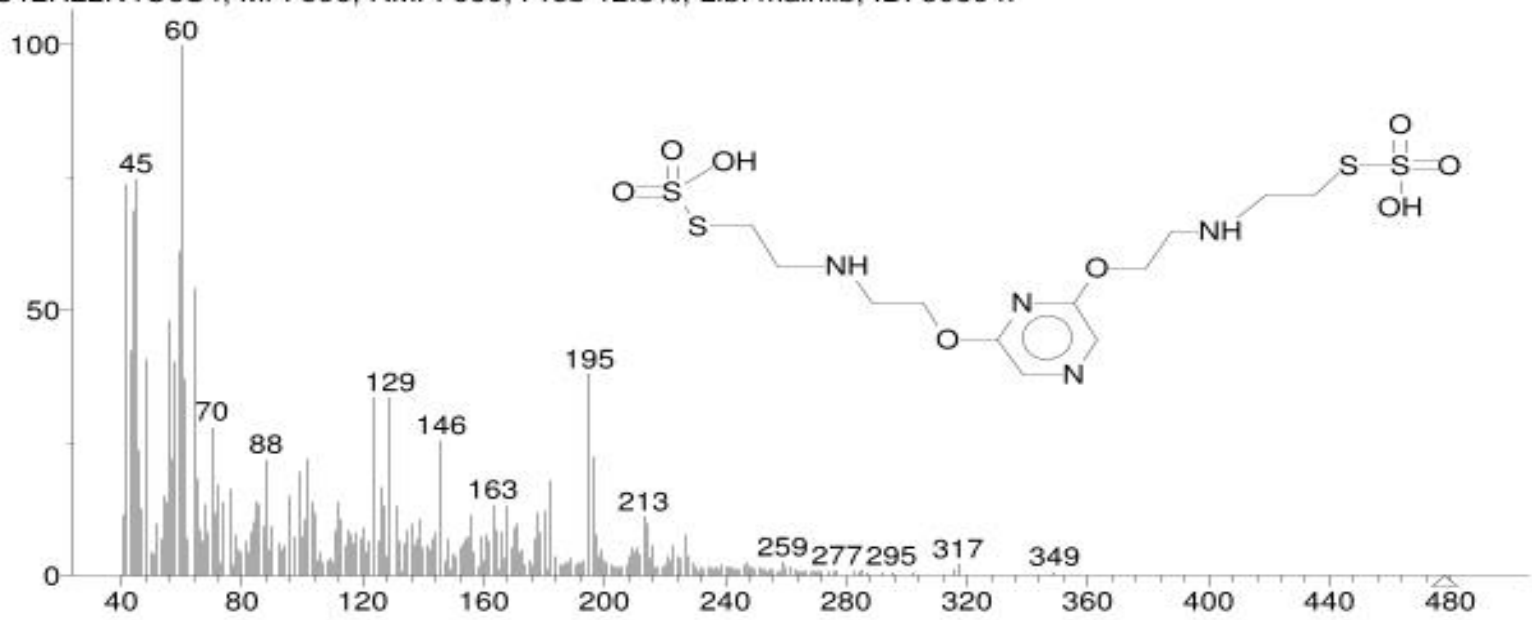

(mainlib) 2,6-Bis[2-[2-S-thiosulfuroethylamino]ethoxy]pyrazine

Figure 2M. The Mass spectra of methanol leaves extract of Mimosa Pudica LINN.

Table 1. FTIR Analysis of Mimosa pudica.

\begin{tabular}{llc}
\hline Absorption frequency $\left(\mathbf{C M}^{-1}\right)$ & Functional Group & Stretching Vibration \\
\hline 3313.6 & Hydroxyl & $\mathrm{O}-\mathrm{H}$ \\
2978.8 & Alkanes & $\mathrm{C}-\mathrm{H}$ \\
2944.8 & Alkanes & $\mathrm{C}-\mathrm{H}$ \\
1705.3 & Carbonyl & $\mathrm{C}=0$ \\
1559.9 & Alkene & $\mathrm{C}=\mathrm{C}$ \\
1474.2 & Alkane & $\mathrm{C}-\mathrm{H}$ \\
1194.6 & Alcohol & $\mathrm{C}-\mathrm{O}$ \\
\hline
\end{tabular}

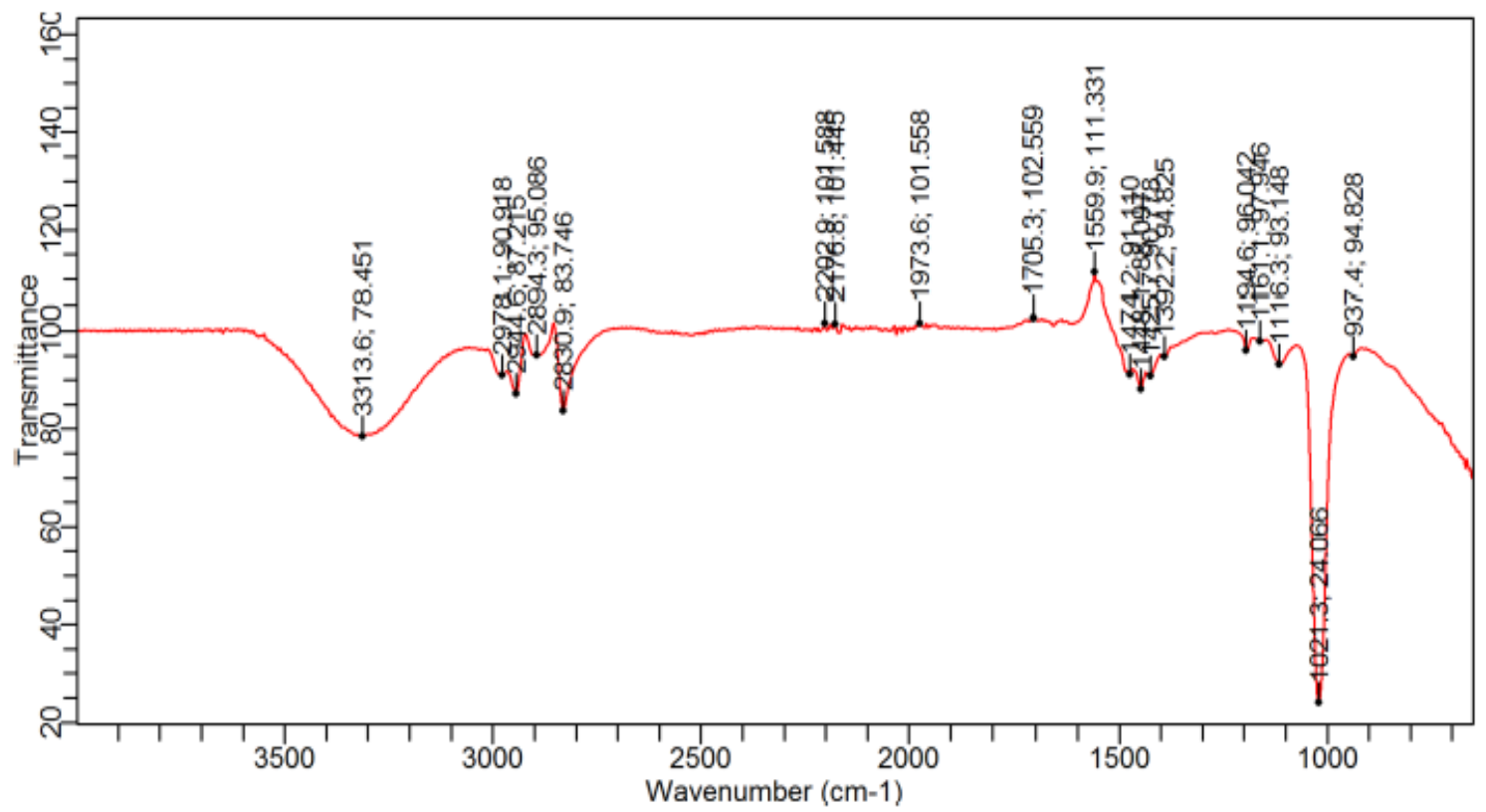

Figure 3. FTIR Spectrum. 
constituents such as alcohol, alkanes, aromatic carboxylic acid, esters and ethers. The presence of the identified phytoconstituents are responsible for various medicinal properties of the plant.

\section{Conclusion}

The presence of thirteen compounds as revealed in the study also provides some pharmacologically basis for its ethno pharmacological uses in the treatment and prevention of various diseases and disorders. Further research is necessary to identify and purify the compounds responsible for antimicrobial and antiviral activity and other biological activities of the plant.

\section{CONFLICT OF INTEREST}

The authors declare that they have no conflict of interest.

\section{REFERENCES}

Ahamefula, A. A., Godwin, I. O., Obike, A. I., Chisom, S. E, Okoronkwo J. C., John Bull, O. E. (2018). GC-MS analysis of bioactive compounds from whole plant chloroform extract of Ageratum conyzoides. International Journal of Medicinal Plants and Natural Products, 4(2), 13-24.

Anyanwu, M. U., \& Okoye, R. C. (2017). Antimicrobial activity of Nigerian medicinal plants. Journal of Intercultural Ethnopharmacology, 6(2), 240.

Autore, G., Caruso, A., Marzocco, S., Nicolaus, B., Palladino, C., Pinto, A., Popolo, A., Sinicropi, M. S., Tommonaro, G., \& Saturnino, C. (2010). Acetamide derivatives with antioxidant activity and potential anti-inflammatory activity. Molecules, 15(3), 2028-2038.

Berest, G. G., Voskoboynik, O. Y., Kovalenko, S. I., Antypenko, O. M., Nosulenko, I. S., Katsev, A. M., \& Shandrovskaya, O. S. (2011). Synthesis and biological activity of novel $\mathrm{N}$-cycloalkyl(cycloalkylaryl)-2-[(3-R-2-oxo-2H-[1, 2, 4] triazino [2, 3-c] quinazoline-6-yl) thio] acetamides. European Journal of Medicinal Chemistry, 46(12), 6066-6074.

Chinmoy, B., \& Nongmaithem, R. C. (2019). The sensitive plant Mimosa pudica: A useful weed. International Journal of Scientific Development and Research, 4(5), 3.

Coimbra, A., \& Magnanini, A. (1993). Considerations sobre Mimosa pudica no combate a arosao superficial. Anucio Braz Econ Floresta Institute Nac Pinho Brazi. Pp. 131-136.

Cortés-Rojas, D. F., Chagas-Paula, D. A., Da Costa, F. B., Souza, C. R. F, \& Oliveira, W. P. (2013). Bioactive compounds in Bidens pilosa L. populations: a key step in the standardization of phytopharmaceutical preparations. Revista Brasileira de Farmacognosia, 23(1), 28-35.

Edoga, H. O., Okwu, D. E., \& Mbaebie B. O. (2005). Phytochemical constituents of some Nigerian Medicinal Plants. African Journal of Biotechnology, 4(7), 685-688.

Ekaiko, M. U., Arinze, A. G., Iwe, C. U., \& Asiegbu, E. (2016). Phytochemical constituents and antimicrobial potency of Aspilia africana. International Journal of Life Sciences Research, 4(1), 9-14.

Ekanem, A. P., \& Udo, F. V. (2009). The Diversity of Medicinal plants in Nigeria: An Overview. In: African Natural Plant Products: New Discoveries and Challenges in Chemistry and
Quality. ACS publications. Pp. 135-147. Retrieved from https://pubs.acs.org/doi/abs/10.1021/bk-2009-1021.ch007.

Faleye, F. J., and Ogundaini,O.A. (2012). Evaluation of antioxidant and antimicrobial activities of two Isolates from Aspilia africana. International Research Journal of Pharmacy 3(7), 135-138.

Fernie, A. R., Trethewey, R. N., Krotzky, A. J., \& Willmitzer, L. (2004). Metabolite profiling: from diagnostics to systems biology. Nature Reviews Molecular Cell Biology, 5(9), 763769.

Hafsa, A., Sakshi, S., Anurag, M., \& Rajiv, G. (2012). Mimosa pudica L. (Laajvanti): An overview. Phamacognosy Review, 6(12), 115-124.

Hussein, E. M., Al-Rooqi, M. M., Abd El-Galil, S. M., \& Ahmed, S. A. (2019). Design, synthesis, and biological evaluation of novel N 4-substituted sulfonamides: acetamides derivatives as dihydrofolate reductase (DHFR) inhibitors. BMC Chemistry, 13, Article Number 91

Kell, D. B., Brown, M., Davey, H. M., Dunn, W. B., Spasic, I., \& Oliver, S. G. (2005). Metabolic footprinting and systems biology: the medium is the message. Nature Reviews Microbiology, 3(7), 557-565.

Lifongo, L. L., Simoben, C. V., Ntie-Kang, F., Babiaka, S. B., \& Judson, P. N. (2014). A bioactivity versus ethnobotanical survey of medicinal plants from Nigeria, West Africa. Natural Products and Bioprospecting, 4, 1-19.

Liu, Z., Zhou, Z., Tian, W., Fan, X., Xue, D., Yu, L., Yu, Q., \& Long, Y. Q. (2012). Discovery of novel 2-N-aryl-substituted benzenesulfonamidoacetamides: orally bioavailable tubulin polymerization inhibitors with marked antitumor activities. Medicinal Chemistry, 7(4), 680-693.

McCarthy, O., Musso-Buendia, A., Kaiser, M., Brun, R., RuizPerez, L. M., Johansson, N. G., Pacanowska, D. G., \& Gilbert, I. H. (2009). Design, synthesis and evaluation of novel uracil acetamide derivatives as potential inhibitors of Plasmodium falciparum dUTP nucleotidohydrolase. European Journal of Medicinal Chemistry, 44(2), 678-688.

McDonald, S., Prenzler, P. D., Antolovich, M., \& Robards, K. (2001). Phenolic content and antioxidant activity of olive extracts. Food chemistry, 73(1), 73-84.

Obute, G. C, \& Osuji, L. C. (2002. Environmental Awareness and Dividends: A discourse. African Journal of Interdisciplinary Studies, 3(1), 90-94.

Okwulehie, I. C., \& Akanwa, F. E. (2013). Antimicrobial activity of ethanol extract of four indigenous plants from South Eastern Nigeria. ARPN Journal of Science and Technology, 3, 350355.

Patro, G., Bhattamisra, S. K., \& Mohanty, B. K. (2016). Effects of Mimosa pudica L. leaves extract on anxiety, depression and memory. Avicenna Journal of Phytomedicine, 6(6): 696-710.

Rohini, K., \& Srikumar, P. S. (2014). Therapeutic role of coumarins and coumarin-related compounds. Journal of Thermodynamics and Catalysis, 5(2), Article Number 130.

Sriram, S., Meenaa, V., Kavitha, V., Agnel, A., \& John, N. (2011). GC-MS study and phytochemical profiling of Mimosa pudica Linn. Journal of Pharmacy Research, 4(3),741-742.

Varnika, S., Ashish, S., \& Imran, A. (2012). A review on ethnomedical and traditional uses of Mimosa pudica. International Research Journal of Pharmacy, 3(2), 41-44.

Zhang, J., Yuan, K., Zhou, W. L., Zhou, J., \& Yang, P. (2011). Studies on the active components and antioxidant activities of the extracts of Mimosa pudica Linn. from southern China. Pharmacognosy Magazine, 7(25), 35-39. 